\title{
Aspects of Spawning Behaviour in Five Gobiids of the Genus Coryphop- terus (Pisces: Gobiidae) in the Caribbean Sea
}

\author{
A. Kramer* ${ }^{1}$, J.L. Van Tassell ${ }^{2}$ and R.A. Patzner ${ }^{1}$ \\ ${ }^{1}$ Department of Organismic Biology, University of Salzburg, Hellbrunnerstr. 34, 5020 Salzburg, Austria \\ ${ }^{2}$ Biology Department, Hofstra University, Hempstead, NY 11549, USA and Department of Ichthyology, American Mu- \\ seum of Natural History, New York, USA
}

\begin{abstract}
Sand dwelling species of Coryphopterus live in shared habitats and were reported to have a similar ecology. Species lineages within the western Atlantic Coryphopterus have recently been reconciled; fish which according to the common keys had formerly been identified as Coryphopterus glaucofraenum could in fact be $C$. glaucofraenum, C. tortugae or $C$. venezuelae and can genetically be clearly separated into different clades. Based on the new taxonomic key, ecological data for five Coryphopterus species are provided; size-sex distribution, number of eggs deposited, inter spawning intervals and courtship behaviour of Coryphopterus dicrus Böhlke and Robins, Coryphopterus eidolon Böhlke and Robins, Coryphopterus thrix Böhlke and Robins, Coryphopterus tortugae Jordan, and Coryphopterus venezuelae Cervigón, were examined in Curacao, Netherland Antilles. For the first time ecological data on C. tortugae and C. venezuelae are provided, which had been previously questioned as distinct species from Coryphopterus glaucofraenum.
\end{abstract}

In all species males reached a greater total length than females. Clutch sizes varied between 423 - 5872 eggs and interspawning intervals were between 5 - 14 days; no preferences for spawning at a particular lunar phase was found.

Gobiids have evolved many different ways of reproduction, for example monogamy, hermaphroditism, sneaking into other nests or bi-directional sex change [1-11]. Number of eggs and fecundity varies widely among and within species, ranging from less than 100 eggs in the small tropical marine goby Eviota lacrimae to over 500000 eggs in the large tropical freshwater goby Awaous guamensis, most of these observations have been based on ovary dissections with only a few studies conducted in the field $[12,13]$. The advantage of experiments conducted in aquaria is that clutch sizes can be documented from a single female, as opposed to natural conditions where the clutch may be produced by several females and be in different stages of development [14].

Coryphopterus species have been reported to have a sequential (protogynous) hermaphroditic life history [12]. Detailed studies in the genus Coryphopterus have suggested that most species in that genus, including C. eidolon, C. dicrus and $C$. thrix are protogynous hermaphrodites, no data on reproduction have been available for $C$. tortugae or $C$. venezuelae $[5,6,13]$. However, some of the previously recorded data might not be accurate as the identification of western Atlantic Coryphopterus species has historically been difficult because of morphological similarity among some species and uncertainty regarding the number of valid species. Baldwin et al. [15] have recently reconciled western Atlantic Coryphopterus species with genetic lineages to determine the number of valid species and provided a revised taxonomic key.

\footnotetext{
*Address correspondence to these authors at the Department of Organismic Biology, University of Salzburg, Hellbrunnerstr. 34, 5020 Salzburg, Austria; Tel: +43 6628044 5619; Fax: +43 6628044 5698;

E-mail: annemariekramer@gmx.net
}

The five investigated species in this study are of similar adult size, and are found in coral reef environments; $C$. eidolon, C. glaucofraenum, C. tortugae and C. venezuelae live associated with sand patches in between coral outcrops, whereas $C$. thrix and C. dicrus are more associated with algae covered coral rocks at the edge of the sandy areas. The aim of this study was to investigate their strategies in reproduction, describe in more detail their ecology, and contribute to the determination of specific factors causing variations within these closely related species.

\section{MATERIALS AND METHODOLOGY}

All studies were performed between April and November 2005, in Curacao, Netherland Antilles. The sample location was the reef south of the Curacao Sea Aquarium (GPS coordinates $+12.08371-68.89645)$. Fish were collected with Quinaldine (2\% in alcohol) and hand nets. Species were identified according to Baldwin et al. [15]. In total 198 fish of different sizes of the five species were collected; $36 C$. dicrus; 56 C. eidolon, 38 C. thrix, 7 C. tortugae, and 67 C. venezuelae. The fish were measured (total length, TL) with a dial calliper (Draper 4817P) to the nearest $0.1 \mathrm{~cm}$ and sex determined by examining genital papillae using a binocular microscope $[3,4,16]$. The fish were placed into aquaria (200 litres) in pairs for reproductive studies. The tanks were supplied with a continuous flow of fresh sea water and kept at an ambient temperature between $28^{\circ}$ and $32^{\circ} \mathrm{C}$. They were exposed to natural light on the outside of the Curacao Sea Aquarium. The bottom of the aquarium was filled with sand and segments of polyvinyl chloride (PVC) pipes between 3 and $5 \mathrm{~cm}$ in diameter and 8 to $10 \mathrm{~cm}$ in length, which provided shelter and breeding substrate for the fish. Five pairs of Coryphopterus eidolon, four of C. thrix and three of $C$. 

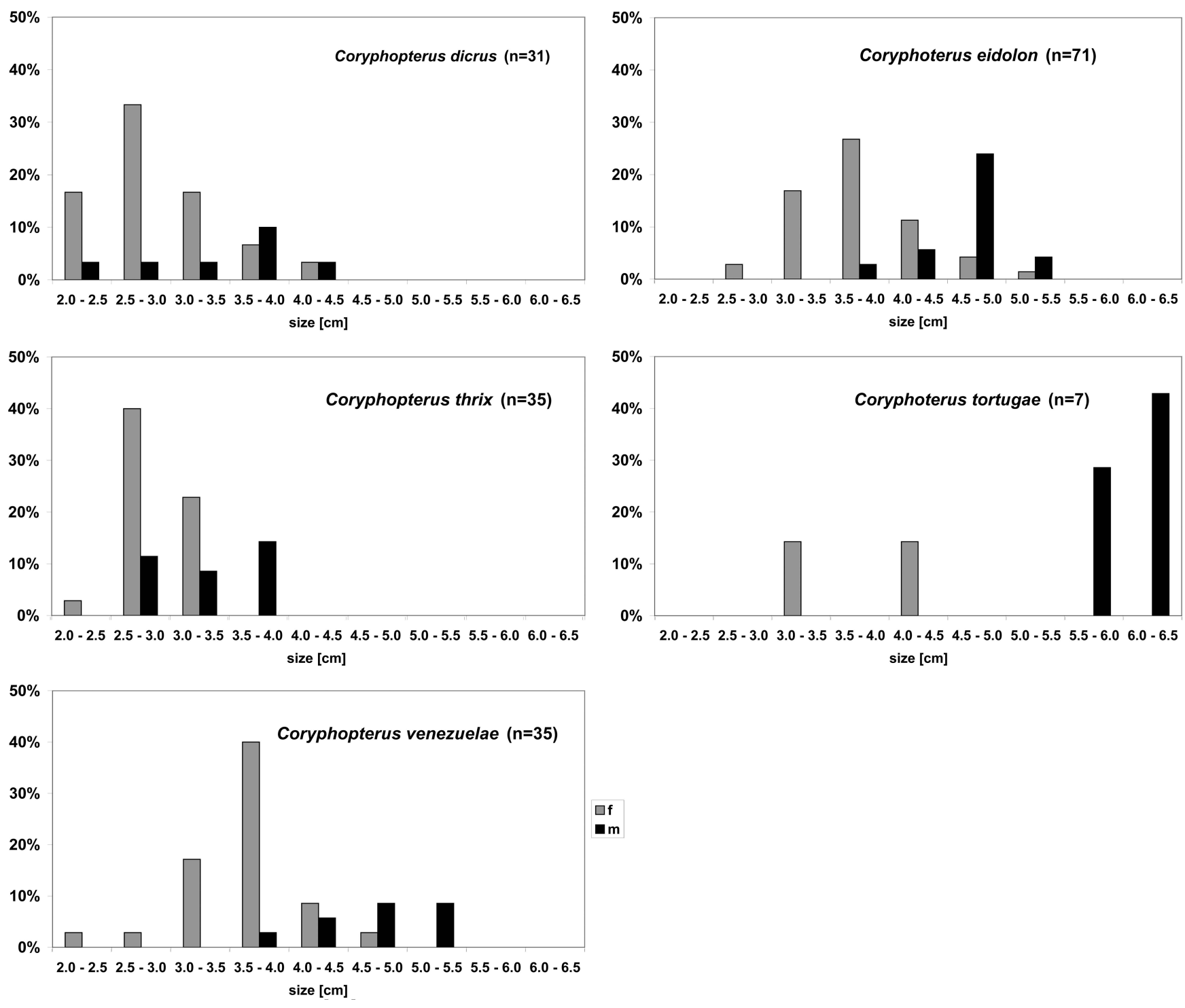

Fig. (1). Size classes - sex distribution in Coryphopterus spp. Significant differences were found between male and female body sizes in $C$. venezuelae and C. tortugae. Species identified by molecular studies.

dicrus were used in the study, as well as nine pairs of Coryphopterus cf glaucofraenum; either $C$. glaucofraenum, $C$. tortugae or $C$. venezuelae (see results for species identification problem). Females used in the spawning experiments were $3.0-4.4 \mathrm{~cm}$ in total length. Spawning was observed in all species. Each PVC pipe was lined with an acetate sheet to allow easy removal of the eggs and clutch size determination [14]. The fish were fed live brine shrimps three times a day and aquaria checked for eggs. After the eggs were laid, they were removed from the PVC pipe, on the acetate sheet, photographed with a digital camera (Olympus C-5060) and counted on the photograph. Statistical analyses were performed with SPSS 16.0 (SPSS Inc., Chicago). Paired t-tests were used to determine significant differences in number of eggs deposited by species and between body sizes of males and females. For differences in body size of males and females the $p$ value was considered significant if less than 0.05, the Bonferroni correction was used for correcting the values of multiple paired t-tests for the number of eggs between the four species and therefore results considered significant at $\mathrm{p}$-values less than 0.0125 .

\section{RESULTS}

For $C$. dicrus 36 individuals were examined (in total length: TL $1.0-4.3 \mathrm{~cm}$ ), for $C$. eidolon 56 individuals (TL $1.3-5.4 \mathrm{~cm}$ ), for $C$. thrix 38 individuals (TL $1.0-3.9 \mathrm{~cm}$ ), for $C$. tortugae 7 individuals (TL $3.2-6.2 \mathrm{~cm}$ ) and for $C$. venezuelae 56 individuals (TL $0.9-5.1 \mathrm{~cm}$ ); the later two had originally been identified as Coryphopterus glaucofraenum according to the standard keys [17-19], but ge- 
Table 1. Number (no.) of Egg Clutches Observed, Range and Mean Number of Eggs, Interval Between Two Consecutive Spawning Events. Numbers of Eggs Deposited are Highly Variable Among Individuals and Species

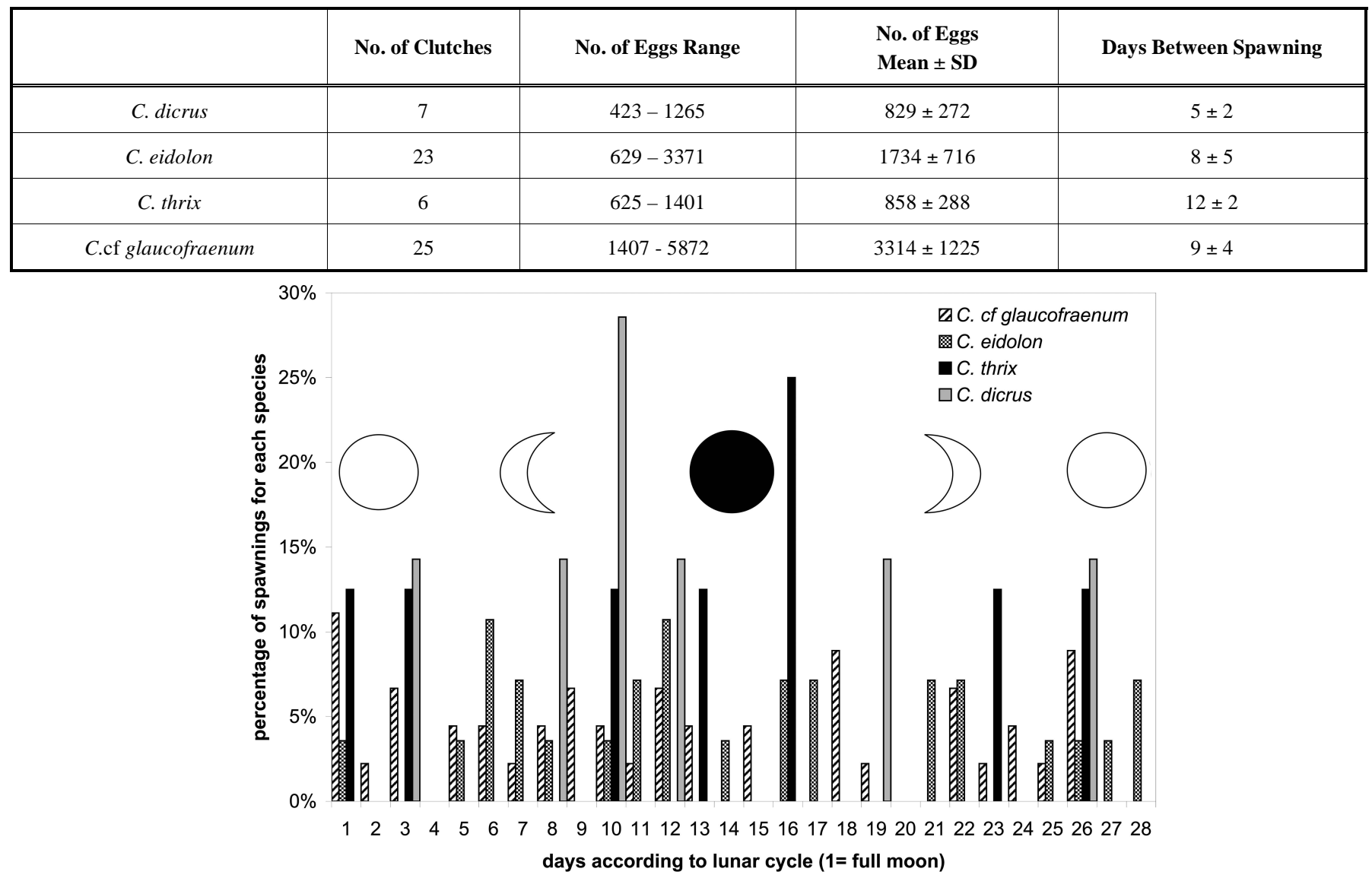

Fig. (2). Distribution of spawning in relation to lunar cycle for Coryphopterus spp. Spawning events occurred randomly during the lunar cycle (full moon $=1$ ).

netic analysis and comparison with the reference sequences provided by Baldwin et al. revealed that some could be assigned to $C$. tortugae and $C$. venezuelae [15]. The nine pair of fish which were identified as $C$. glaucofraenum and used for spawning experiments could not be re-identified, but due to a large set of data from these fish, the results are included in the present paper and referred to as $C$. cf glaucofraenum. The same term is used when referring to other authors and their previous studies with results on C. glaucofraenum, as the fish identity is now questionable.

Total length and sex are presented in Fig. (1): In this study males in all Coryphopterus species attained a greater length than females, differences between male and female body sizes did show significant differences in body length between males and females in $C$. tortugae and $C$. venezuelae (CI $95 \%$ ). The total length (TL) at which genital papillae could visually be differentiated was similar for all species; $2.2 \mathrm{~cm}$ in $C$. dicrus, $2.7 \mathrm{~cm}$ for $C$. eidolon, $2.3 \mathrm{~cm}$ for $C$. thrix, $3.2 \mathrm{~cm}$ for $C$. tortugae and $2.4 \mathrm{~cm}$ for $C$. venezuelae. Data on number of eggs and intervals between spawning events for $C$. dicrus, C. eidolon, $C$. thrix and $C$. cf glaucofraenum are summarized in Table 1, a t-test with a Bonferroni correction (CI 98.75\%) resulted in no significant differences in number of eggs between the species. There was no visual evidence for a strong lunar spawning pattern: $C . d i$ - crus and $C$. thrix appeared to spawn preferentially around new moon, but a larger data set is needed to confirm if a preference exists (Fig. 2). No evidence for a relationship between female body length and the number of eggs laid was observed (Table 2); but this will also have to be confirmed with additional data. Courtship behaviour was observed in all species and was very similar. A detailed description for Coryphopterus dicrus is given: The male swam towards the female with very fast movements of all fins. After that, he remained inside the PVC tube most of the time, while the female remained in front of it or inside. The male's colouration changed: ventral fins becoming a dark grey colour, the transparent anal fins showing a silvery-bluish margin. The male then moved all his fins while swimming in and out of the tube. The female moved close to the entrance of the tube, positioning herself at a $90^{\circ}$ angle to the front of the tube, and hence displaying her lateral side to the male. The male continued swimming in and out of the tube, rapidly moving all fins, except his caudal fin. The female started swimming in and out of the tube repeatedly; the male was simultaneously swimming around and towards her, exhibiting an intense colour display of blue and yellow on its body and all of its fins. The female maintained her natural colouration. In both fish the genital papilla was erect, swollen and clearly visible. The male continued to display and swim in circles towards 
Table 2. Total Length (TL) of Females and Number of Eggs Observed in Each Spawning Event. There is no Visual Evidence of any Relation Between Female Body Length and Number of Eggs

\begin{tabular}{|c|c|c|c|c|c|c|}
\hline & TL $[\mathbf{c m}]$ & $\mathbf{1}^{\text {st }}$ Spawning & $\mathbf{2}^{\text {nd }}$ Spawning & $\mathbf{3}^{\text {rd }}$ Spawning & $\mathbf{4}^{\text {th }}$ Spawning & $\mathbf{5}^{\text {th }}$ Spawning \\
\hline \hline C. dicrus & 3.8 & 830 & - & - & - \\
\hline C. eidolon & 4.4 & 1110 & 629 & - & - \\
\hline C. thrix & - & - & - & - & - \\
\hline C.cf glaucofraenum & 4.1 & 3336 & 3478 & - & - \\
\hline C.cf glaucofraenum & 3.5 & 2211 & 2453 & 2124 & - \\
\hline C.cf glaucofraenum & 3.0 & 2886 & 2864 & 2836 & - \\
\hline C.cf glaucofraenum & 4.2 & 4856 & 4199 & 3537 & 5872 & - \\
\hline C.cf glaucofraenum & 4.1 & 1564 & 1736 & - & - \\
\hline C.cf glaucofraenum & 4.1 & 1930 & 4664 & - & - \\
\hline
\end{tabular}

the female, moving his tail fin rapidly. During another spawning event a male was observed displaying his body laterally and widely opening his mouth. The female entered and exited the tube a number of times; whenever the male swam towards her, she turned away, got closer to the tube, and finally entered backwards.

Spawning was observed several times for each of the Coryphopterus species. In all events, the female deposited eggs, in a single layer, on the ceiling and lateral walls of the PVC pipe, while the male swam next to her, fertilizing the eggs. A detailed description of their eggs, attaching structure and developing larvae has been given by Kramer and Patzner [20].

\section{DISCUSSION}

Spawning and reproductive behaviour in Coryphopterus species is similar to that described for other gobiid species: the female lays a batch of eggs in a single layer, attached to the substrate while the male fertilizes them [14, 20-22]. Cole [6] states that protogyny appears to be widespread, if not universal in the genus Coryphopterus. Experimental studies within the genus Coryphopterus have shown the ability of $C$. dicrus, C. eidolon, $C$. cf glaucofraenum and $C$. thrix to change sex and were confirmed by histological examination of gonad structure [13]. Findings in the present study which show that mean total length of males is larger than that of females is supportive evidence for protogyny, but experimental studies and dissection of gonad tissue will be required to confirm this for $C$. venezuelae and $C$. tortugae [23].

How long the fish live and what causes them to change sex under natural conditions is not known. Their maximum size has been reported to be $5.0 \mathrm{~cm}$ for $C$. dicrus and $C$. thrix, $6.0 \mathrm{~cm}$ for $C$. eidolon [24], $7.5 \mathrm{~cm}$ for $C$. venezuelae [25] and $6.2 \mathrm{~cm}$ for C. tortugae (this study). For the first time data are available on the size - sex distribution of $C$. tortugae and $C$. venezuelae and results indicate that they are protogynous hermaphrodites as in other Coryphopterus species. The results for $C$. tortugae still have to be confirmed with a larger sample size.
Sexual maturity in Coryphopterus cf glaucofraenum has been reported by Forrester and Steele [26] as occurring between a standard length (SL) of 2.2 and $2.5 \mathrm{~cm}$, they did not describe the method employed to obtain those data, but refer to unpublished data. These data are close to the total length at which we could determine if fish were male or female by their genital papillae.

It is difficult to predict the number of eggs deposited under natural conditions; they can be different from numbers obtained in the laboratory and males can guard eggs of more than one female at the same time [27].

In many gobiids of temperate and subtropical zones spawning periods occur primarily in spring/summer and last for several months with a consecutive "reproductional break" $[1,28,29]$. In the present study undertaken from April to November 2005 continuous reproduction was observed and spawning in all species appeared to occur independent of lunar phases, these results will have to be confirmed on a larger data set. Sponaugle and Cowen [28] state that there might be a connection between spawning and lunar cycle in C. cf glaucofraenum, which appears to have a peak spawning period near the moon's third quarter; their data were calculated back from larval stages. It will be necessary to determine what triggers spawning events in the field as laboratory settings can bias results. The arrangement of the stable male-female pairs do not reflect the social arrangement in the field, where dominant males probably mate with multiple females during most spawning bouts, as observed in other protogynous gobiids [27]. This will also give conclusions on the minimum inter spawning interval of 3 days, observed in the present study, which is close to the $4-6$ days reported for other tropical, reef associated gobiids, such as Paragobiodon echinocephalus and Asterroptryx semipunctata, again from observations made in lab conditions [14, 30]. Topics for future studies remain: the variability in the number of eggs (up to 3100) between different clutches, laid by the same female; factors which determine the length of an inter spawning interval and if its length has an effect of the number of eggs deposited and under what circumstances and how frequently the fish change sex under natural conditions. 


\section{CONCLUSION}

The species C. eidolon, C. dicrus, C. cf glaucofraenum, C. thrix, C. tortugae and C. venezuelae have very similar patterns in reproduction and results support previous findings which suggest them to be protogynous. Number of eggs deposited differ greatly between different clutches and the reason for that remains a topic for future studies. No visual evidence has been found that reproductive behaviour in captivity is related to the lunar phases or body length to the number of eggs a female deposits.

\section{ACKNOWLEDGEMENTS}

We thank the Curacao Sea Aquarium, especially Steve Piontek, for providing SCUBA equipment and laboratory facilities, José G. Bernal Rodríguez for his field assistance. The field work was partly financed by the University of Salzburg and Land Salzburg.

\section{REFERENCES}

[1] Colin PL. The Neon Gobies: The Comparative Biology of the Genus Gobiosoma, Subgenus Elacatinus, (Pisces: Gobiidae) in the Tropical Western North Atlantic Ocean. T.F.H. Publications: Neptune 1975.

[2] Robertson DR, Justines G. Protogynous hermaphroditism and gonochorism in four Caribbean reef gobies. Environ Biol Fish 1982; 7: 137-42.

[3] Miller PJ. In: Potts GW, Wotton RJ, Eds. Fish Reproduction. Strategies and Tactics. Academic Press: London 1984; pp. 119-53.

[4] Thresher RE. Reproduction in Reef Fishes. T.F.H. Publications: Neptune 1984.

[5] Cole KS. Predicting the potential for sex change on the basis of ovarian structure in gobiid fishes. Copeia 1988; 4: 1082-6.

[6] Cole KS. Patterns of gonad structure in hermaphroditic gobies (Teleostei: Gobiidae). Environ Biol Fish 1989; 28: 125-42.

[7] Magnhagen C. Alternative reproductive tactics and courtship in the common goby. J Fish Biol 1998; 53: 130-7.

[8] Munday PL, Caley MJ, Jones GP. Bi-directional sex change in a coral dwelling goby. Behav Ecol Sociobiol 1998; 43: 371-7.

[9] Munday PL. Bi-directional sex change: testing the growth-rate advantage model. Behav Ecol Sociobiol 2002; 52: 247-54.

[10] Whiteman EA, Côté IM. Social monogamy in the cleaning goby Elacatinus evelynae: ecological constraints or net benefits? Anim Behav 2003; 66: 281-91.

[11] Munday PL, White JW, Warner RR. A social basis for the development of primary males in a sex-changing fish. Proc Biol Sci 2006; 273: 2845-51

[12] Thacker CE, Cole KS. Phylogeny and evolution of the gobiid genus Coryphopterus. Bull Mar Sci 2002; 70: 837-50.
[13] Cole KS, Shapiro DY. Gonad structure and hermaphroditism in the gobiid genus Coryphopterus (Teleostei: Gobiidae). Copeia 1990; 4: 996-1003.

[14] Privitera LA. Characteristics of egg and larval production in captive bluespotted gobies. J Fish Biol 2001; 58: 1211-20.

[15] Baldwin CC, Weigt LA, Smith DG, Mounts JH. Reconciling genetic lineages with species in Western Atlantic Coryphopterus (Teleostei: Gobiidae). Smithson Contrib Mar Sci 2009; in press.

[16] Cole KS, Robertson DR. Protogyny in the Caribbean reef goby, Coryphopterus personatus: gonad ontogeny and social influences on sex change. Bull Mar Sci 1988; 42: 317-33.

[17] Böhlke JE, Robins CR. A revision of the gobiid genus Coryphopterus. Proceedings of the Academy of Natural Sciences; Philadelphia: 1960; 112 (5): pp. 103-28.

[18] Böhlke JE, Chaplin CG. Fishes of the Bahamas and adjacent tropical waters. Livingston Publishing Company: Wynnewood 1968.

[19] Murdy EO. Gobiidae. In: Carpenter KE, Ed. The Living Marine Resources Of The Western Central Atlantic. Volume 3: Bony Fishes Part 2 (Opistognathidae to Molidae), Sea Turtles And Marine Mammals. FAO Species identification guide for fishery purposes and American Society of Ichthyologists and Herpetologists. Special Publication No. 5, 2002; pp. 1375-2127.

[20] Kramer A, Patzner AR. Morphological and developmental studies on the eggs of four Coryphopterus species (Actinopterygii: Gobiidae) in the Caribbean Sea. Acta Ichthyol Piscat 2008; 38: 97-102.

[21] Herler J, Patzner RA, Hilgers H. Notes on the egg envelope and number of oocytes in two Gobius species (Teleostei: Gobiidae) from the northern Adriatic. Z Fischk 2006; 8: 1-7.

[22] Giulianini PG, Ferrero EA. Ultrastructural aspects of the ovarian follicle and egg envelope of the sea-grass goby Zosterisessor ophiocephalus (Osteichthyes, Gobiidae). Ital J Zool 2000; 68: 2937.

[23] Sadovy Y, Shapiro DY. Criteria for the diagnosis of hermaphroditism in fishes. Copeia 1987; 136-56.

[24] Robins CR, Ray GC. A Field Guide to Atlantic Coast Fishes of North America. Houghton Mifflin Company: Boston 1986.

[25] Cervigón F. Los Peces Marinos de Venezuela. Fundación Scientifica Los Roques: Caracas 1994; vol. III.

[26] Forrester GE, Steele MA. Predators, prey refuges, and the spatial scaling of density-dependent prey mortality. Ecology 2004; 85 1332-42.

[27] Kroon FJ, De Graf M, Liley NR. Social organisation and competition for refuge and nest sites in Coryphopterus nicholsii (Gobiidae), a temperate protogynous reef fish. Environ Biol Fish 2000; 57: 401-11.

[28] Sponaugle S, Cowen RK. Larval durations and recruitment patterns of two Caribbean gobies (Gobiidae): contrasting early life histories in demersal spawners. Mar Biol 1994; 120: 133-43.

[29] Gordina AD, Duka LA, Oven LS. Sexual dimorphism, feeding and reproduction of Gobius bucchichi in the Black Sea. J Ichthyol 1974; 14: 623-9.

[30] Kuwamura T, Yogo Y, Nakashima Y. Size-assortative monogamy and parental egg care in a coral goby Paragobiodon echinocephalus. Ethology 1993; 95: 65-75.

Received: December 04, $2008 \quad$ Revised: February 10, 2009

Accepted: February 13, 2009

(c) Kramer et al.; Licensee Bentham Open.

This is an open access article licensed under the terms of the Creative Commons Attribution Non-Commercial License (http://creativecommons.org/licenses/by-nc/3.0/) which permits unrestricted, non-commercial use, distribution and reproduction in any medium, provided the work is properly cited. 